\title{
精品在线开放课程教学资源的开发与应用研究 一以高职《建筑构造》课程为例
}

\section{Research on the Development and Application of Teaching Resources of Top-Quality Online Open Courses}

— Taking the Course of Architectural Structure of Higher Vocational School as an Example 吴伟

Wei Wu

\begin{abstract}
江西建设职业技术学院土木系
中国・江西 南昌 330200

Department of Civil Engineering, Jiangxi

College of Construction,

Nanchang, Jiangxi, 330200, China

基金项目:2018 年度 江西省教育厅教 改项目 “高职院校精品在线开放课程教 学资源的开发与应用研究一以《建筑 构造》课程为例” (项目编号: JXJG-1872-6)。
\end{abstract}

【摘要】论文从在线课程教学特点出发, 以《建筑构造》课程为例研究了在线课程教学资 源的开发和制作过程，并结合高职院校教育的特点将在线课程资源应用于实际教学过程 中, 给出了高职院校进行在线课程资源应用与推广思路, 为今后高职院校课程建设与教学 改革提供借鉴。

【Abstract】Based on the teaching characteristics of online course, this paper takes Architectural Structure course as an example to study the development and making process of online course teaching resources. Combined with the characteristics of higher vocational education, this paper applies online course resources to the actual teaching process, and gives the ideas of applying and popularizing online course resources in higher vocational colleges, so as to provides reference for the curriculum construction and teaching reform in higher vocational colleges.

【关键词】在线课程;教学资源; 应用研究

【Keywords】online course; teaching resources; application research 【DOI】10.36012/sde.v2i3.1633

\section{1 前言}

随着信息技术的发展和计算机移动电子产品的发展很普 及,现代教育进入了新的发展时期, 以数字化教学资源为核心 的网络在线教学越来越多的应用到课程教学过程中, 如何设 计与开发在线开放课程教学资源, 是课程教学的关键 ${ }^{[1]}$ 。同时 结合网络在线学习者的教学特点, 将在线课程资源应用于教 学活动中, 探索课程建设的发展策略, 从而提高教学效果, 具 有重要的现实意义。

\section{2 在线开放课程教学资源的开发}

本文以高职院校土木工程专业核心课程《房屋构造》课程 为例介绍在线课程资源开发思路。

\section{1 课程定位}

《建筑构造》课程是建筑工程技术、监理、等专业的一门重 要的必修专业核心课程, 应培养的相应专项技能为: 绘制与识 读施工图的能力、运用所学知识解决房屋建筑工程实际问题 能力、考取岗位职业资格证书的能力。通过《建筑构造》课程学
习, 培养学生掌握民用和工业建筑构造的组成和基本构造原 理、常见的构造作法, 以及建筑施工图的识读, 同时能够运用 所学知识解决房屋建筑工程实际问题, 配合其他有关课程的 学习, 为今后从事建筑工程施工与管理、工程建设监理、工程 质量与安全管理、工程经营与造价管理等工作奠定基础 ${ }^{[2]}$ 。

\section{2 课程资源的设计}

以“学生自主学习为主”的教学理念, 设计开发《建筑构 造》在线课程数字化课程教学资源。本课程教学内容以, 初识 建筑物、基础与地下室、墙体的认知、楼层的认知、屋顶的认 知、楼梯的认知、门窗的认知、变形缝的认知, 八个方面进行 任务设计, 把理论和实践内容紧密结合在一起开发课程教学 资源。

\section{3 课程教学资源开发过程、制作方法}

视频教学资源是在线课程教学的核心资源, 下面以视频 教学资源的开发来介绍课程资源开发过程。视频教学资源的 开发主要由, 确定教学内容、设定教学目标和教学设计过程等 组成。 


\subsection{1 确定教学内容}

《建筑构造》是土木工程建筑施工技术专业的核心专业课 程, 重点培养学生掌握建筑的基本组成和构造原理, 以及读懂 建筑施工图。利用自己所学的基本知识, 解决建筑施工中的具 体问题。《建筑构造》这门课程总共分为: 初识建筑物、基础与 地下室、墙体的认知、楼层的认知、屋顶的认知、楼梯的认知、 门窗的认知、变形缝的认知等八个项目, 其中 “楼梯的设计” 是 该课程的一个教学重点与难点, 具有很重要的代表性。

\subsection{2 设定教学目标}

“楼梯设计”教学目标总共有以下三点: (1)认识和掌握楼 梯的构造和组成; (2)认识和掌握楼梯的尺度设计要求; (3)认识 和掌握楼梯设计图的识读与绘制。

\subsection{3 视频教学资源的设计开发过程}

视频教学资源的设计开发过程主要由开头引入部分、主 体内容部分和最后结尾部分组成。单个视频资源的总时长控 制在 10 分钟左右, 最长不超过 15 分钟。引入部分, 也是课程 教学内容的开头, 引入部分尽量简短, 而且要一目了然, 时间 最好控制在 1 2 分钟。原因是视频一般都很简短。尽量采用 项目教学来先开引入部分, 如直接向学生提出问题: 如何设计 楼梯, 这样可以直接进入主题、明确教学内容和目标。主体部 分, 也是课程教学内容的关键, 要做到由浅入深的开展, 以便 学生可以很容易地接受和学习教学内容。主题内容是教学的 核心部分, 时间一般控制在 5 6 分钟。主体部分内容的展开 可以这样进行: 先向学生介绍楼梯的构造组成, 其次介绍楼梯 的设计要求、步骤等, 最后以一实例介绍楼梯的设计, 从而有 层次感地介绍教学内容。结尾部分, 是课程教学内容的总结, 目的是总结和归纳教学知识点, 时长控制在 2 3 分钟, 并提供 经典练习题, 供学生练习和检查课程学习的效果。从而方便学 生课后的自主学习。

\section{3 在线开放课程教学资源的应用}

教师应重视线上教学方法的研究和实践, “以学生为中 心”, 实现信息技术与学科教学的深度融合, 从而达到了在线 课程资源的综合与高效应用。

\section{1 线上教学模式是基于“慕课”的混合式教学} 模式

慕课是大规模的开放式网络在线课程。慕课的特点是课 程学习自主性强, 使用工具多元化、易于使用, 学习受众面广。 这些特点正满足了混合式教学中在线学习的需要, 成为“互联 网+”信息化时代教学改革的切人点。基于慕课在线学习平台 的混合式教学模式, 可以改变学习者学习方式自主力不强、学
习枯燥、进度不统一、学习考核评价单一等弊端, 实现了学习 方式个性化、人性化、评价过程多样化和科学化。以此研究探 索提出了基于 “以学生为中心”线上教学模式设计应遵循的原 则, 构建适应高职院校线上教学“以职业教育为背景, 以问题 为核心、以任务为驱动”的线上课程教学模式。

\section{2 线上教学主要采用问题探究、自主探究、任}

\section{务驱动、等教学方法}

通过建设与使用教学资源、设计多元全程考核评价机制、 课前下发学习任务、增强课堂教学活力、课后作业及时发布及 时反馈、及时反馈学生在线问题, 增强在线课堂活力, 提高在 线教学效果。教学资源的具体应用可分为课前、课中和课后三 部分。课前通过课程平台, 推送课程资源, 让学生提前预习本 节课内容, 通过在线学习并做几个简单的在线测试, 了解学生 的学习情况。在教学中, 首先采用问题导入的方法,引入实际 生活中的案例及三维动画演示提出问题, 激发学生的联想, 把 学生带入课堂, 从而启发学生自主学习, 推进课堂教学活动的 进行。课后学生利用自己的业余时间登入学习平台进行自主 学习, 可以是电脑也可以是手机等移动设备, 这种在任何时候 都可以进行的学习方式, 可以帮助学生更加有效的学习课程 知识, 从而以达到解决问题的目的。

\section{3 在线开放课程的过程考核}

课程考核内容、方式突出以专业岗位职业能力和综合素 质为核心的目标, 按照课程模块针对知识目标、技能目标和态 度目标制定了相应的考核要求。重在培养学生的能力, 激发学 生的学习自主性,培养其创新意识和创造能力。在线上与线下 的教学过程中, 以提高学生综合能力为最终目标, 努力促进课 程考核方式的改变, 由以前传统的考核方式向全面过程考核 转变。

基于慕课的混合式教学模式结合了线上线下两种教学形 式的优点, 使得教育信息化时代下的信息技术与教育深度地 融合在了一起, 实现了学习者课前、课中、课后三个学习阶段 线上与线下的有机结合, 实现信息技术与学科教学的深度融 合, 真正实现了“以学生为中心”的课程教学理念, 从而达到了 在线课程资源的综合与高效应用。

\section{4 在线课程资源的开发与应用应该注意 的一些问题}

\section{1 提高在线课程资源建设水平和开发效率}

在线课程资源的开发与研究目前还缺乏统一设计理念 和思路, 缺乏科学的在线课程资源资源建设规范。课程资 源的开发与建设应该注意以下几点: 第一, 要重视在线课

(下转第 145 页) 


\section{4 结论}

师德是指教师和一切教育工作者在从事教育活动中必 须遵守的道德规范和行为准则, 加强师德师风建设对增强 教师实践教学水平和综合素养、提高学生创新创业实践能 力、提升高校整体育人质量具有重要的激励与促进作用。学 校的师德师风建设需要每位工作者自律、自省、自警, 不单 是教师的职责, 本文将与教育活动相关工作者均作为考核 对象, 根据岗位类别设计了不同的评价体系, 重点突出岗位 职责, 提高师德建设的针对性和有效性, 对参与考核者自身 能够起到督促作用，提高参与者对于师德师风建设的正确 认识, 进一步加强对自身的要求和规范, 进而提高服务水平 和创新能力。

\section{参考文献}

[1]中共中央国务院关于全面深化新时代教师队伍建设改革的意 见[EB/OL].http://www.gov.cn/zhengce/2018-01/31/content_5262659.htm, 2018-01-31

[2]教育部等七部门印发《关于加强和改进新时代师德师风建设 的意见》的通知[EB/OL].http://www.moe.gov.cn/jyb_xwfb/gzdt_gzdt/ s5987/201912/t20191216_412125.html,2019-12-16.

[3]蒋佩云.高校教师师德评价指标体系构建及实证研究[J].湖南 科技学院学,2015(4):141-145.

[4]范明,陈佳秀. 高校工科教师评价指标体系构建实证研究 [J]. 北 京工业大学学报:社会科学版,2017(4):72-78.

[5]刘辰, 李雪飞. 基于 ANP 的高校师德评价模型研究[J]. 现代教 育科学(高教研究),2018(11):78-84.

[6]董鹏刚.新时代下高校教师师德评价指标体系构建研究[J].德 育研究,2018(19):57-88.

\section{（上接第 141 页）}

程资源的建设与开发, 特别是“以学生为中心”的在线课程 资源开发; 第二, 不但要注重对单个知识点的在线课程资 源的开发, 还要更加注重对整个课程在线课程资源程建 设; 第三, 要特别注重团队的协作与开发合作, 提高在线课 程资源建设效率, 特别是整门课程在线课程资源程的开发 建设效率,避免教师个人或学校低水平的重复建设在线课 程资源程。

\section{2 促进和提高了教师专业水平的发展}

在线课程资源的核心资源是在线课程资源视频，在整个 在线课程资源微视频的录制过程中, 从理论讲解到实践操作, 都由教师个人完成, 教师在创作在线课程资源的过程中, 要求 教师做到教学语言要简明扼要, 逻辑性强, 易于理解, 讲解过 程要流畅紧凑, 从而提高了教师知识讲解与总结的能力; 同时 为拓展知识点, 就必须查阅资料去充实内容, 才不会显得空泛 和空洞。那么, 在拓展学生的视野的同时, 也丰富了教师的教 学资源。从而提升教师的课堂教学水平。做在线课程资源, 需 要了解并掌握许多相关的软件,比如录屏软件、PPT、截屏软 件等。这促使要求教师掌握现代信息技术,跟上并赶超时代的 步伐。在线课程资源, 最终让教师从习惯的细节中追问、思 考、发现、变革, 由学习者变为开发者和创造者, 从而促进和提 高了教师专业水平的发展。

\section{3 加强师生交流及在线课程资源实施应用效 果评价}

学生在线课程资源学习结束后, 可以通过各种渠道和方 式对在线课程学习评价,如学生座谈、现场调研、网络、学习评 价系统等。通过学生的评价及反馈的信息, 不仅可以加强师生 之间的交流,还可以促进教师对课程资源内容的补充和调整, 从而真正达到一学生学习为中心的目的, 促进教学质量的稳 步提升。

\section{5 结语}

在线课程教学资源是教育信息化的重要组成部分, 支撑 着教育信息化的发展。如何开发与设计在线课程教学资源, 提 高教学资源的高效综合应用, 这是课程教学改革与研究的重 要方向。同时结合网络在线学习者的教学特点, 将在线课程资 源应用于教学活动中, 探索课程建设的发展思路, 从而实现信 息技术与学科教学的深度融合, 取得在线课程教学显著效果, 也需要教师与学生的共同付出努力。

\section{参考文献}

[1]胡铁生. “在线课程资源”: 区域教育信息资源发展的新趋势 [J]. 电化教育研究, 2011(10):61-65.

[2]张风密.信息化教学背景下《自动变速器 拆装与检修》课程资 源的开发与研究[J].汽车维修与修理,2018(10):29. 